\title{
Willingness to Vaccinate against COVID-19 Declines in Australia, Except in Lockdown Areas
}

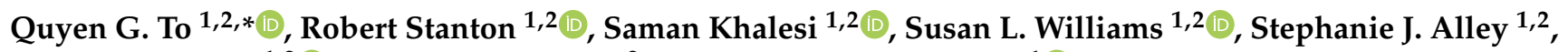 \\ Tanya L. Thwaite ${ }^{1,2}{ }^{(}$, Andrew S. Fenning ${ }^{2}$ and Corneel Vandelanotte ${ }^{1}(\mathbb{D}$ \\ 1 Appleton Institute, Central Queensland University, Rockhampton 4701, Australia; \\ r.stanton@cqu.edu.au (R.S.); s.khalesi@cqu.edu.au (S.K.); s.p.williams@cqu.edu.au (S.L.W.); \\ s.alley@cqu.edu.au (S.J.A.); t.thwaite@cqu.edu.au (T.L.T.); c.vandelanotte@cqu.edu.au (C.V.) \\ 2 School of Health, Medical and Applied Sciences, Central Queensland University, Rockhampton 4701, \\ Australia; a.fenning@cqu.edu.au \\ * Correspondence: q.to@cqu.edu.au; Tel.: +61-7-4930-6456
}

\section{check for}

updates

Citation: To, Q.G.; Stanton, R.; Khalesi, S.; Williams, S.L.; Alley, S.J.; Thwaite, T.L.; Fenning, A.S.; Vandelanotte, C. Willingness to Vaccinate against COVID-19 Declines in Australia, Except in Lockdown Areas. Vaccines 2021, 9, 479 . https://doi.org/10.3390/ vaccines 9050479

Academic Editor: Ralph J. DiClemente

Received: 8 April 2021

Accepted: 6 May 2021

Published: 10 May 2021

Publisher's Note: MDPI stays neutral with regard to jurisdictional claims in published maps and institutional affiliations.

Copyright: (c) 2021 by the authors. Licensee MDPI, Basel, Switzerland. This article is an open access article distributed under the terms and conditions of the Creative Commons Attribution (CC BY) license (https:// creativecommons.org/licenses/by/ $4.0 /)$.
Abstract: This study investigates changes in willingness to vaccinate against COVID-19 and the effect of the extended restrictions in metropolitan Victoria on this change. Longitudinal and repeated crosssectional data were collected from online surveys distributed in April, between July and August, and December 2020. Australian adults who were $\geq 18$ years old were recruited through email lists, social media networks, and paid Facebook advertisement. Willingness to vaccinate against COVID-19 was self-reported. The results showed that participants were more willing to vaccinate if the vaccine was safe at survey 1 (longitudinal: adjusted $\mathrm{OR}(\mathrm{aOR})=1.88,95 \% \mathrm{CI}=1.38,2.56$; cross-sectional: $\mathrm{aOR}=3.73$, $95 \% \mathrm{CI}=2.55,5.45$ ) and survey 2 (longitudinal: $\mathrm{aOR}=1.54,95 \% \mathrm{CI}=1.19,2.00$; cross-sectional: $\mathrm{aOR}=2.48$, $1.67,3.67)$, compared to survey 3 . The change in willingness to vaccinate if the vaccine was safe and effective was not significant for those in Metropolitan Victoria; but was for those living in other Australian locations at survey $1(\mathrm{OR}=2.13,95 \% \mathrm{CI}=1.64,2.76)$ and survey $2(\mathrm{OR}=1.62,95 \% \mathrm{CI}=1.30,2.01)$, compared to survey 3 . Willingness to vaccinate even if a vaccine had not been proven safe decreased at survey $3(\mathrm{OR}=2.02,95 \% \mathrm{CI}=1.14,3.57)$ for those living in Metropolitan Victoria. In conclusion willingness to vaccinate against COVID-19 decreased over time among Australians, except for those living in metropolitan Victoria, where an additional strict and prolonged lockdown was implemented around the time of survey 2. Either the experience of the lockdown, or the presence of the COVID-19 virus itself had a positive influence on participants' willingness to vaccinate, even if such a vaccine was not yet proven to be safe and effective.

Keywords: vaccine hesitancy; anti-vaccination; vaccine sentiment; pandemic; lockdown

\section{Introduction}

Vaccine hesitancy has been an issue since the development of the first vaccine. In 2019, the World Health Organization ranked vaccine hesitancy as one of the top ten threats to global health [1]. One study showed that three-quarters of American pediatricians encountered a parent who postponed or even refused for their child to receive at least one vaccine within a one-year period [2]. The percentage of non-medical vaccination exemption has also risen in the last two decades in the U.S. [3]. This is likely due to complacency and low perceived risk of infection, as studies have found vaccination rates increased in places where outbreaks occurred [4,5].

Since the World Health Organization declared COVID-19 a pandemic on 11 March 2020 [6], 219 countries and territories worldwide have reported more than 120 million confirmed cased and 2.7 million deaths (23 March 2021) [7]. In Australia, there have been 29,206 confirmed cases and 909 deaths (23 March 2021) [8]. Several vaccines have been developed and are supported for implementation globally due to evidence of their safety and efficacy (e.g., Pfizer with an efficacy of 95\% [9] and AstraZeneca with an efficacy of 
62.1\% [10] have been approved for use in the US [11], Australia [12], and UK [13,14]). Given the severity of COVID-19, and its far-reaching implications on everyday life, one might expect that willingness to vaccinate would be high. On the other hand, given the rapid development and roll-out of COVID-19 vaccines, there may still be public concerns regarding safety and effectiveness.

Results of recent Australian studies reporting on COVID-19 vaccine hesitancy are inconsistent. One study found that the percentage of people willing to receive a COVID-19 vaccine increased $1.91 \%$ between June and July 2020 [15], whereas Alley et al. (2021) found that percentages of people willing to vaccinate decreased between April (87\%) and August 2020 (85\%) [16]. The disparities highlight the need to continuously track vaccine hesitancy to assist government efforts with achieving high vaccination rates.

This brief study updates the results of the Alley et al. (2021) on the changes in willingness to vaccinate for COVID-19 by including new data from a third survey conducted in December 2020. This study also aimed to investigate the impact of additional extended restrictions in the metropolitan Victoria on willingness to vaccinate for COVID-19.

\section{Methods}

\subsection{Study Design and Participants}

Australian adults ( $\geq 18$ years) were invited to complete an online survey, which was created and hosted on the Qualtrics platform. Email lists, social media networks, and paid Facebook advertisement were used for recruitment. The survey was preceded by an information sheet outlining the purpose of the study and the risks and benefits of participation. Electronic consent was obtained via submission of survey responses. Three surveys were distributed, with the first one open between 9 and 19 April 2020, the second between 30 July and 16 August 2020, and the third between 1 and 25 December 2020. Participants were asked to provide an email address if they were interested in participating in future survey distribution, allowing for the collection of longitudinal data. New participants were also recruited using the same methods for the second and the third surveys. The project was approved by Central Queensland University's Human Research Ethics Committee (Approval number 22332).

At the time of distributing the first survey, Australia was in the first wave of infection and restrictions on leaving home, travelling, and public gatherings were in place $[8,17,18]$. When the second survey was distributed, COVID-19 community transmission rates were very low throughout Australia, except for Victoria where rates of infection were increasing [8]. As a result, a second strict and prolonged lockdown was announced in Victoria whereas most restrictions were lifted in other states [17]. This second lockdown measures in Victoria was stricter than the first and included new measures, such as closure of childcare centres, no private gatherings, and an 8pm to 5am curfew [19]. During the third survey, rates of infection were under control, and most COVID-19 restrictions were eased in all Australian states and territories [17].

\subsection{Measures}

Demographic characteristics included age in years, gender (male, female), years of education, and weekly household income ( $<1000$ AUD, 1000-<2000 AUD, $\geq 2000$ AUD). Chronic disease status of participants was assessed using the question "Have you ever been told by a doctor that you have any chronic health problems?", with response options of "yes" or "no". Postcodes were used to classify the living location of participants as either "metropolitan Victoria" (where the lockdown occurred) or "other locations".

Participants' willingness to vaccinate were assessed using three questions. The first was "If a new vaccine for COVID-19 was released that was proven to be safe and effective, I would get vaccinated immediately". The second was "If a new vaccine for COVID-19 was released but had not yet been proven to be safe and effective, I would get vaccinated immediately"; the intention of asking this question was to try to indirectly gauge whether the disruption, discomfort and potential frustration with the COVID-19 situation could 
entice people to vaccinate even when a vaccine has not been proven entirely safe. The third was "Even before the COVID-19 pandemic, I have always vaccinated myself against diseases when recommended by health professionals". There were five response options "strongly disagree", "disagree", "neutral", "agree", and "strongly agree", which were grouped into either "agree" or "disagree/neutral" for the analysis.

\subsection{Analysis}

SAS v9.4 was used for data analysis. Two datasets were created and analyzed separately. The longitudinal dataset included participants with data from at least two surveys. To ensure that the assumption of independence was not violated, the repeated crosssectional data excluded those in the longitudinal dataset and only included participants that were different from each other for every survey. Descriptive statistics, including percentages and means with standard deviations, were generated and presented for each of the three surveys, and for the two datasets. To examine the changes in willingness to vaccinate over time, generalized linear mixed models were used for the longitudinal data, and generalized linear models were used for the repeated cross-sectional data. A binary distribution and logit link were used in both models. For each outcome, a bivariate model and a model adjusted for age, gender, years of education, household income, and chronic disease status were executed. Due to multiple comparisons, estimates were adjusted using the simulation option available in PROC GLIMMIX. Crude and adjusted odds ratios (95\% confidence intervals) were reported for each outcome.

Due to the longitudinal nature of the analysis, the effect of the lockdown in metropolitan Victoria on the change in willingness to vaccinate was examined using only the longitudinal data. A generalized linear mixed model, including time, location, and an interaction term between time and location, was executed. A logit link function and binary distribution was also used. Adjustment for multiple comparisons was made using the simulation option in PROC GLIMMIX. Changes in willingness to vaccinate were presented as odds ratios for metropolitan Victoria and other locations. All $p$-values were two-tailed and considered significant if $<0.05$.

\section{Results}

Table 1 shows participant characteristics of both longitudinal and repeated crosssectional samples. In general, sample characteristics were similar across all three surveys. The majority of participants were women and had household incomes of less than \$2000 AUD/week. Mean age was approximately 52 years with a mean duration of education of approximately 16 years.

Table 2 shows changes in willingness to vaccinate over time. A decline in willingness to vaccinate if the vaccine was proven to be safe and effective was observed for both samples. For the longitudinal sample, participants were more willing to vaccinate at survey 1 (adjusted $\mathrm{OR}=1.88,95 \% \mathrm{CI}=1.38,2.56)$ and survey 2 (adjusted $\mathrm{OR}=1.54,95 \% \mathrm{CI}=1.19$, 2.00), compared to survey 3. Similar results but larger effects were found for the repeated cross-sectional sample that participants were more willing to vaccinate at survey 1 (adjusted $\mathrm{OR}=3.73,95 \% \mathrm{CI}=2.55,5.45$ ) and survey 2 (adjusted $\mathrm{OR}=2.48,1.67,3.67$ ), compared to survey 3 . Although there was a decline in percentages of participants willing to vaccinate if the available vaccine had not yet been proven to be safe and effective, the difference was not statistically significant for the longitudinal sample and only significant when comparing survey 1 and survey 3 (adjusted OR $=1.75,95 \% C I=1.06,2.89$ ) for the repeated crosssectional sample. Unexpectedly, the results for the question "Even before the COVID-19 pandemic, I have always vaccinated myself against diseases when recommended by health professionals" were inconsistent with longitudinal data showing a significant increase in agreement with this statement but repeated cross-sectional data showing a significant decrease in agreement. 
Table 1. Characteristics for the samples.

\begin{tabular}{|c|c|c|c|c|c|c|}
\hline \multirow[b]{2}{*}{ Longitudinal } & \multicolumn{2}{|c|}{ Survey 1} & \multicolumn{2}{|c|}{ Survey 2} & \multicolumn{2}{|c|}{ Survey 3} \\
\hline & $\mathbf{n}$ & $\%$ or Mean (SD) & $\mathbf{n}$ & $\%$ or Mean (SD) & $\mathbf{n}$ & $\%$ or Mean (SD) \\
\hline Age (years) & 638 & $52.5(14.3)$ & 858 & $53.2(14.1)$ & 560 & $53.5(14.1)$ \\
\hline \multicolumn{7}{|l|}{ Gender } \\
\hline Male & 199 & 31.3 & 273 & 31.9 & 165 & 29.6 \\
\hline Female & 436 & 68.7 & 584 & 68.1 & 393 & 70.4 \\
\hline Years of Education & 638 & $16.5(4.7)$ & 858 & $16.6(4.7)$ & 560 & $16.6(4.7)$ \\
\hline \multicolumn{7}{|l|}{ Household income/week } \\
\hline$<1000$ AUD & 148 & 26.5 & 213 & 28.6 & 142 & 29.3 \\
\hline 1000-<2000 AUD & 176 & 31.5 & 220 & 29.5 & 138 & 28.5 \\
\hline$\geq 2000$ AUD & 234 & 41.9 & 313 & 42.0 & 205 & 42.3 \\
\hline \multicolumn{7}{|l|}{ Chronic disease } \\
\hline No & 335 & 52.5 & 435 & 50.7 & 271 & 48.4 \\
\hline Yes & 303 & 47.5 & 423 & 49.3 & 289 & 51.6 \\
\hline \multicolumn{7}{|l|}{ Location } \\
\hline Other Australian locations & 550 & 86.2 & 711 & 82.9 & 453 & 80.9 \\
\hline Metropolitan Victoria & 88 & 13.8 & 147 & 17.1 & 107 & 19.1 \\
\hline Cross-Sectional & n & $\%$ or Mean (SD) & $\mathbf{n}$ & $\%$ or Mean (SD) & $\mathbf{n}$ & $\%$ or Mean (SD) \\
\hline Age (years) & 1007 & $49.4(15.3)$ & 623 & $54.0(15.2)$ & 376 & $55.4(14.9)$ \\
\hline \multicolumn{7}{|l|}{ Gender } \\
\hline Male & 347 & 34.7 & 236 & 38.4 & 175 & 47.6 \\
\hline Female & 652 & 65.3 & 379 & 61.6 & 193 & 52.5 \\
\hline Years of Education & 1008 & $16.0(5.3)$ & 625 & $15.8(5.4)$ & 377 & $14.7(5.4)$ \\
\hline \multicolumn{7}{|l|}{ Household income/week } \\
\hline$<1000$ AUD & 233 & 27.0 & 192 & 37.0 & 112 & 38.1 \\
\hline 1000-<2000 AUD & 251 & 29.1 & 140 & 27.0 & 84 & 28.6 \\
\hline$\geq 2000$ AUD & 378 & 43.9 & 187 & 36.0 & 98 & 33.3 \\
\hline \multicolumn{7}{|l|}{ Chronic disease } \\
\hline No & 541 & 53.7 & 314 & 50.2 & 214 & 56.8 \\
\hline Yes & 467 & 46.3 & 311 & 49.8 & 163 & 43.2 \\
\hline \multicolumn{7}{|l|}{ Location } \\
\hline Other Australian locations & 879 & 87.2 & 443 & 70.9 & 300 & 79.6 \\
\hline Metropolitan Victoria & 129 & 12.8 & 182 & 29.1 & 77 & 20.4 \\
\hline
\end{tabular}

Table 3 shows longitudinal data for changes in willingness to vaccinate by location. There was no significant difference in willingness to vaccinate if the vaccine was proven to be safe and effective for those living in Metropolitan Victoria at survey 1 and survey 2 , compared to survey 3 . However, a significant decrease was found for those living in other Australian locations at survey $1(\mathrm{OR}=2.13,95 \% \mathrm{CI}=1.64,2.76)$ and survey 2 $(\mathrm{OR}=1.62,95 \% \mathrm{CI}=1.30,2.01)$, compared to survey 3 . Willingness to vaccinate even if a vaccine had not been proven safe and effective increased at survey 2 and decreased at survey $3(\mathrm{OR}=2.02,95 \% \mathrm{CI}=1.14,3.57)$ for those living in Metropolitan Victoria. Direction of associations was not different for those living in Metropolitan Victoria and those in other locations. 
Table 2. Changes in willingness to vaccinate over time.

\begin{tabular}{|c|c|c|c|c|c|c|c|c|c|c|}
\hline \multirow{2}{*}{$\begin{array}{l}\text { Longitudinal } \\
\text { Data }\end{array}$} & \multicolumn{2}{|c|}{$\begin{array}{l}\text { Survey } 1 \\
(\mathrm{n}=638)\end{array}$} & \multicolumn{2}{|c|}{$\begin{array}{l}\text { Survey } 2 \\
(n=858)\end{array}$} & \multicolumn{2}{|c|}{$\begin{array}{l}\text { Survey } 3 \\
(n=560)\end{array}$} & \multicolumn{2}{|c|}{ Crude OR ( $95 \%$ CI) } & \multicolumn{2}{|c|}{ Adjusted OR $(95 \% \text { CI })^{+}$} \\
\hline & n & $\%$ & n & $\%$ & $\mathbf{N}$ & $\%$ & T1 vs. T3 & T2 vs. T3 & T1 vs. T3 & T2 vs. T3 \\
\hline \multicolumn{11}{|c|}{ If a new vaccine for COVID-19 was released that was proven to be safe and effective, I would get vaccinated immediately } \\
\hline Disagree/Neutral & 82 & 12.9 & 127 & 14.8 & 118 & 21.1 & 1.00 & 1.00 & 1.00 & 1.00 \\
\hline Agree & 556 & 87.2 & 731 & 85.2 & 442 & 78.9 & $\begin{array}{c}1.91^{* * *} \\
(1.43,2.54)\end{array}$ & $\begin{array}{c}1.59 * * * \\
(1.25,2.02)\end{array}$ & $\begin{array}{c}1.88^{* * *} \\
(1.38,2.56)\end{array}$ & $\begin{array}{c}1.54^{* * *} \\
(1.19,2.00)\end{array}$ \\
\hline \multicolumn{11}{|c|}{ If a new vaccine for COVID-19 was released but had not yet been proven to be safe and effective, I would get vaccinated immediately } \\
\hline Disagree/Neutral & 549 & 86.1 & 729 & 85.0 & 494 & 88.2 & 1.00 & 1.00 & 1.00 & 1.00 \\
\hline Agree & 89 & 14.0 & 129 & 15.0 & 66 & 11.8 & $\begin{array}{c}1.26 \\
(0.89,1.78)\end{array}$ & $\begin{array}{c}1.38 * \\
(1.01,1.88)\end{array}$ & $\begin{array}{c}1.19 \\
(0.81,1.73)\end{array}$ & $\begin{array}{c}1.31 \\
(0.94,1.84)\end{array}$ \\
\hline \multicolumn{11}{|c|}{ Even before the COVID-19 pandemic, I have always vaccinated myself against diseases when recommended by health professionals } \\
\hline Disagree/Neutral & 115 & 18.0 & 127 & 14.8 & 55 & 9.8 & 1.00 & 1.00 & 1.00 & 1.00 \\
\hline Agree & 523 & 82.0 & 731 & 85.2 & 505 & 90.2 & $\begin{array}{c}0.57^{* * *} \\
(0.44,0.75)\end{array}$ & $\begin{array}{c}0.69 * * * \\
(0.54,0.88)\end{array}$ & $\begin{array}{c}0.61 \text { *** } \\
(0.46,0.82)\end{array}$ & $\begin{array}{c}0.74^{*} \\
(0.57,0.96)\end{array}$ \\
\hline \multirow{2}{*}{$\begin{array}{c}\text { Cross-Sectional } \\
\text { Data }\end{array}$} & \multicolumn{2}{|c|}{$\begin{array}{c}\text { Survey } 1 \\
(\mathrm{n}=1008)\end{array}$} & \multicolumn{2}{|c|}{$\begin{array}{l}\text { Survey } 2 \\
(\mathrm{n}=625)\end{array}$} & \multicolumn{2}{|c|}{$\begin{array}{l}\text { Survey } 3 \\
(\mathrm{n}=377)\end{array}$} & \multicolumn{2}{|c|}{ Crude OR $(95 \%$ CI) } & \multicolumn{2}{|c|}{ Adjusted OR $(95 \% \mathrm{CI})$} \\
\hline & n & $\%$ & n & $\%$ & $\mathbf{N}$ & $\%$ & T1 vs. T3 & T2 vs. T3 & T1 vs. T3 & T2 vs. T3 \\
\hline \multicolumn{11}{|c|}{ If a new vaccine for COVID-19 was released that was proven to be safe and effective, I would get vaccinated immediately } \\
\hline Disagree/Neutral & 151 & 15.0 & 131 & 21.0 & 148 & 39.3 & 1.00 & 1.00 & 1.00 & 1.00 \\
\hline Agree & 857 & 85.0 & 494 & 79.0 & 229 & 60.7 & $\begin{array}{c}3.67^{* * *} \\
(2.65,5.07)\end{array}$ & $\begin{array}{c}2.44^{* * *} \\
(1.74,3.42)\end{array}$ & $\begin{array}{c}3.73^{* * *} \\
(2.55,5.45)\end{array}$ & $\begin{array}{c}2.48^{* * *} \\
(1.67,3.67)\end{array}$ \\
\hline \multicolumn{11}{|c|}{ If a new vaccine for COVID-19 was released but had not yet been proven to be safe and effective, I would get vaccinated immediately } \\
\hline Disagree/Neutral & 837 & 83.0 & 529 & 84.6 & 337 & 89.4 & 1.00 & 1.00 & 1.00 & 1.00 \\
\hline Agree & 171 & 17.0 & 96 & 15.4 & 40 & 10.6 & $\begin{array}{c}1.72 * \\
(1.11,2.67)\end{array}$ & $\begin{array}{c}1.53 \\
(0.96,2.45)\end{array}$ & $\begin{array}{c}1.75^{*} \\
(1.06,2.89)\end{array}$ & $\begin{array}{c}1.60 \\
(0.95,2.71)\end{array}$ \\
\hline \multicolumn{11}{|c|}{ Even before the COVID-19 pandemic, I have always vaccinated myself against diseases when recommended by health professionals } \\
\hline Disagree/Neutral & 185 & 18.4 & 131 & 21.0 & 112 & 29.7 & 1.00 & 1.00 & 1.00 & 1.00 \\
\hline Agree & 823 & 81.7 & 494 & 79.0 & 265 & 70.3 & $\begin{array}{c}1.88^{* * *} \\
(1.36,2.61)\end{array}$ & $\begin{array}{c}1.59 * * \\
(1.12,2.27)\end{array}$ & $\begin{array}{c}1.58 * \\
(1.07,2.32)\end{array}$ & $\begin{array}{c}1.37 \\
(0.91,2.07)\end{array}$ \\
\hline
\end{tabular}

${ }^{*} p<0.05,{ }^{* *} p<0.01,{ }^{* * *} p<0.001 .{ }^{+}$Adjusted for age, gender, years of education, household income, and chronic disease status.

Table 3. Percentage of agreement at three surveys and changes by location for longitudinal data.

\begin{tabular}{|c|c|c|c|c|c|c|c|c|}
\hline & \multicolumn{2}{|c|}{ Survey $1(n=638)$} & \multicolumn{2}{|c|}{ Survey $2(n=858)$} & \multicolumn{2}{|c|}{ Survey $3(n=560)$} & \multirow[t]{2}{*}{ T1 vs. T3 } & \multirow[t]{2}{*}{ T2 vs. T3 } \\
\hline & n & $\%$ & n & $\%$ & n & $\%$ & & \\
\hline \multicolumn{9}{|c|}{ If a new vaccine for COVID-19 was released that was proven to be safe and effective, I would get vaccinated immediately } \\
\hline $\begin{array}{c}\text { Other } \\
\text { Australian } \\
\text { location }\end{array}$ & 481 & 87.5 & 599 & 84.3 & 349 & 77.0 & $\begin{array}{c}2.13^{* * *} \\
(1.64,2.76)\end{array}$ & $\begin{array}{c}1.62^{* * *} \\
(1.30,2.01)\end{array}$ \\
\hline $\begin{array}{l}\text { Metropolitan } \\
\text { Victoria }\end{array}$ & 75 & 85.2 & 132 & 89.8 & 93 & 86.9 & $\begin{array}{c}0.99 \\
(0.52,1.86)\end{array}$ & $\begin{array}{c}1.45 \\
(0.82,2.54)\end{array}$ \\
\hline
\end{tabular}

If a new vaccine for

COVID-19 was released but had not yet been proven to be safe and effective, I would get vaccinated immediately

\begin{tabular}{|c|c|c|c|c|c|c|c|c|}
\hline $\begin{array}{c}\text { Other } \\
\text { Australian } \\
\text { location }\end{array}$ & 75 & 13.6 & 95 & 13.4 & 52 & 11.5 & $\begin{array}{c}1.24 \\
(0.90,1.72)\end{array}$ & $\begin{array}{c}1.24 \\
(0.92,1.66)\end{array}$ \\
\hline $\begin{array}{c}\text { Metropolitan } \\
\text { Victoria }\end{array}$ & 14 & 15.9 & 34 & 23.1 & 14 & 13.1 & $\begin{array}{c}1.28 \\
(0.64,2.57) \\
\end{array}$ & $\begin{array}{c}2.02 * \\
(1.14,3.57)\end{array}$ \\
\hline \multicolumn{9}{|c|}{ Even before the COVID-19 pandemic, I have always vaccinated myself against diseases when recommended by health professionals } \\
\hline $\begin{array}{l}\text { Other } \\
\text { Australian } \\
\text { location }\end{array}$ & 449 & 81.6 & 597 & 84.0 & 405 & 89.4 & $\begin{array}{c}0.59 * * * \\
(0.47,0.75)\end{array}$ & $\begin{array}{c}0.66^{* * *} \\
(0.53,0.82)\end{array}$ \\
\hline $\begin{array}{l}\text { Metropolitan } \\
\text { Victoria }\end{array}$ & 74 & 84.1 & 134 & 91.2 & 100 & 93.5 & $\begin{array}{c}0.43^{* *} \\
(0.23,0.79)\end{array}$ & $\begin{array}{c}0.88 \\
(0.50,1.55)\end{array}$ \\
\hline
\end{tabular}




\section{Discussion}

This study aimed to investigate the change in willingness to vaccinate during the COVID-19 pandemic, and the effect of extended restrictions on this change. The findings show that willingness to vaccinate declined over time in both longitudinal and repeated cross-sectional samples. This is likely due to Australia's success in controlling the spread and mortality rates of COVID-19, hence perceived risk of infection among Australians may have reduced over time, resulting in an increase in vaccine hesitancy [4,5]. As information about perceived risk of infection was not collected, it was not accounted for in the analysis. In addition, willingness to vaccinate was higher among Australians ( $>85 \%)$ in April, compared to people in other countries, including France (74\%) [20], New Zealand (74\%) [21], the UK (64\%) [22], and the USA (58\%) [23], which may make it easier to decline.

Despite not being the main focus of this study, differences in the results from the longitudinal and cross-sectional data for the question "Even before the COVID-19 pandemic, I have always vaccinated myself against diseases when recommended by health professionals" was worth noting. A possible explanation for the repeated cross-sectional data could be that the samples were different for the three surveys. For the longitudinal sample, it is unclear why the percentages of agreement increased. It could be that the changes in the COVID-19 situation may somehow have influenced the way the participants responded to this question. However, given the self-report measure, the reason may just be a response bias for both longitudinal and cross-sectional data.

The results also suggest that the lockdown during survey 2 may help delay the decrease in participants' willingness to vaccinate in metropolitan Victoria. Percentages of willingness to vaccinate even when the vaccine had not yet been proven to be safe and effective increased during the lockdown (survey 2) but then, in survey 3 , they decreased to a level similar as reported in survey 1 . An explanation for these changes could be that people living in places with strict lockdown conditions may be eager to have lockdown restrictions lifted and were therefore more willing to take extra measures, including vaccination (safe or not) to stop the spread of COVID-19. This result is supported by findings from a study in Italy that willingness to vaccinate against COVID-19 decreased as restrictions were relaxed [24].

To our knowledge, this is the first study investigating the possible effect of a lockdown on willingness to vaccinate against COVID-19 in a sample of Australian adults. The study included a large longitudinal sample with measures taken at times with high and low COVID-19 rates, allowing the examination of changes over time. However, there are some limitations. Survey respondents were generally older, had high levels of education, and a greater proportion were female. Therefore, generalizability may be limited to the demographics of included participants. Future studies may be needed with a sample more representative of the general Australian population. Furthermore, willingness to vaccinate was self-reported, and therefore may be subjected to recall bias. Finally, with this study design, it is not possible to control for unknown confounders.

In conclusion, willingness to vaccinate against COVID-19 decreased over time among Australians, with the exception of those living in the metropolitan Victoria where a strict lockdown was implemented around the time of survey 2. The lockdown appeared to help not only delay the decrease in willingness to receive a vaccine that was proven to be safe and effective, but also to increase willingness to vaccinate even when the vaccine had not yet been proven to be safe. Strategies to improve willingness to vaccinate among Australians are needed. Vaccination that is implemented in areas with strict restrictions may be more accepted.

Author Contributions: Conceptualization, Q.G.T., R.S., S.K., S.L.W., S.J.A., T.L.T., A.S.F. and C.V.; Data curation, T.L.T.; Formal analysis, Q.G.T. and S.L.W.; Methodology, Q.G.T., R.S., S.K., S.J.A., T.L.T., A.S.F. and C.V.; Writing—original draft, Q.G.T.; Writing—review and editing, R.S., S.K., S.L.W., S.J.A., T.L.T., A.S.F. and C.V. All authors have read and agreed to the published version of the manuscript. 
Funding: This research received no external funding. S.J.A. is supported by an Early Career Fellowship from the National Heart Foundation of Australia (ID 102609). S.K. is also supported by an Early Career Fellowship from the National Heart Foundation of Australia (ID 102584).

Institutional Review Board Statement: The study was conducted according to the guidelines of the Declaration of Helsinki and approved by Central Queensland University's Human Research Ethics Committee (Approval number 22332).

Informed Consent Statement: It was obtained from all subjects involved in the study.

Data Availability Statement: The data presented in this study are available on request. The data are not publicly available due to ethical considerations.

Conflicts of Interest: The authors declare no conflict of interest.

\section{References}

1. World Health Organization. Ten Threats to Global Health in 2019. 2019. Available online: https://www.who.int/news-room/ spotlight/ten-threats-to-global-health-in-2019 (accessed on 30 November 2020).

2. American Academy of Pediatrics. Documenting Parental Refusal to Have Their Children Vaccinated. 2013. Available online: https:/ / www.aap.org/en-us/documents/immunization_refusaltovaccinate.pdf (accessed on 9 May 2021).

3. Bednarczyk, R.A.; King, A.R.; Lahijani, A.; Omer, S.B. Current landscape of nonmedical vaccination exemptions in the United States: Impact of policy changes. Expert Rev. Vaccines 2019, 18, 175-190. [CrossRef] [PubMed]

4. Baumgaertner, B.; Ridenhour, B.J.; Justwan, F.; Carlisle, J.E.; Miller, C.R. Risk of disease and willingness to vaccinate in the United States: A population-based survey. PLoS Med. 2020, 17, e1003354. [CrossRef] [PubMed]

5. Oster, E. Does disease cause vaccination? Disease outbreaks and vaccination response. J. Health Econ. 2018, 57, 90-101. [CrossRef] [PubMed]

6. World Health Organization. Listings of WHO's Response to COVID-19. 2020. Available online: https://www.who.int/news / item/29-06-2020-covidtimeline (accessed on 2 April 2021).

7. Worldometer. Countries Where COVID-19 has Spread 2021. Available online: https://www.worldometers.info/coronavirus / countries-where-coronavirus-has-spread (accessed on 23 March 2021).

8. Australian Government, Department of Health. Coronavirus (COVID-19) Current Situation and Case Numbers. 2020. Available online: https:/ / www.health.gov.au/news/health-alerts/novel-coronavirus-2019-ncov-health-alert/coronavirus-covid19-current-situation-and-case-numbers (accessed on 22 March 2021).

9. Polack, F.P.; Thomas, S.J.; Kitchin, N.; Absalon, J.; Gurtman, A.; Lockhart, S.; Perez, J.L.; Marc, G.P.; Moreira, E.D.; Zerbini, C.; et al. Safety and Efficacy of the BNT162b2 mRNA Covid-19 Vaccine. N. Engl. J. Med. 2020, 383, 2603-2615. [CrossRef] [PubMed]

10. Voysey, M.; Clemens, S.A.C.; Madhi, S.A.; Weckx, L.Y.; Folegatti, P.M.; Aley, P.K.; Angus, B.; Baillie, V.L.; Barnabas, S.L.; Bhorat, Q.E.; et al. Safety and efficacy of the ChAdOx1 nCoV-19 vaccine (AZD1222) against SARS-CoV-2: An interim analysis of four randomised controlled trials in Brazil, South Africa, and the UK. Lancet 2021, 397, 99-111. [CrossRef]

11. Immunization Action Coalition. Vaccine Timeline. 2021. Available online: https://www.immunize.org/timeline (accessed on 26 April 2021).

12. Department of Health. Australia's Vaccine Agreements Australian Government. 2021. Available online: https://www.health.gov. au/node/18777/ australias-vaccine-agreements (accessed on 4 May 2021).

13. Mueller, B.U.K. Approves Pfizer Coronavirus Vaccine, a First in the West. The New York Times. 2 December 2020. Available online: https:/ / www.nytimes.com/2020/12/02/world/europe/pfizer-coronavirus-vaccine-approved-uk.html (accessed on 26 April 2021).

14. Kahn, J. A complete timeline of what's going on with the AstraZeneca COVID vaccine. Fortune. 1 April 2021. Available online: https:/ / fortune.com/2021/04/01/astrazeneca-covid-vaccine-timeline-news-latest-update (accessed on 26 April 2021).

15. Dodd, R.H.; Pickles, K.; Nickel, B.; Cvejic, E.; Ayre, J.; Batcup, C.; Bonner, C.; Copp, T.; Cornell, S.; Dakin, T.; et al. Concerns and motivations about COVID-19 vaccination. Lancet Infect. Dis. 2020, 21, 161-163. [CrossRef]

16. Alley, S.J.; Stanton, R.; Browne, M.; To, Q.G.; Khalesi, S.; Williams, S.L.; Thwaite, T.; Fenning, A.; Vandelanotte, C. As the Pandemic Progresses, How Does Willingness to Vaccinate against COVID-19 Evolve? Int. J. Environ. Res. Public Health 2021, $18,797$. [CrossRef] [PubMed]

17. Australian Government, Department of Health. Coronavirus (COVID-19) Restrictions. 2020. Available online: https://www. health.gov.au/news/health-alerts/novel-coronavirus-2019-ncov-health-alert/coronavirus-covid-19-restrictions (accessed on 22 March 2021).

18. Stanton, R.; To, Q.G.; Khalesi, S.; Williams, S.L.; Alley, S.J.; Thwaite, T.L. Depression, Anxiety and Stress during COVID-19: Associations with Changes in Physical Activity, Sleep, Tobacco and Alcohol Use in Australian Adults. Int. J. Environ. Res. Public Health 2020, 17, 4065. [CrossRef] [PubMed]

19. Health and Human Services, Victoria State Government. Victoria's Restriction Levels. 2020. Available online: https://www.dhhs. vic.gov.au/victorias-restriction-levels-covid-19 (accessed on 22 March 2021). 
20. Peretti-Watel, P.; Seror, V.; Cortaredona, S.; Launay, O.; Raude, J.; Verger, P.; Fressard, L.; Beck, F.; Legleye, S.; L'Haridon, O.; et al. A future vaccination campaign against COVID-19 at risk of vaccine hesitancy and politicisation. Lancet Infect. Dis. 2020, 20, 769-770. [CrossRef]

21. Thaker, J.; Menon, V. Aotearoa New Zealand Public Attitudes to COVID-19 Vaccine; Massey University: Palmerston North, NI, New Zealand, 2020

22. Sherman, S.M.; Smith, L.E.; Sim, J.; Amlôt, R.; Cutts, M.; Dasch, H.; Rubin, G.J.; Sevdalis, N. COVID-19 vaccination intention in the UK: Results from the COVID-19 vaccination acceptability study (CoVAccS), a nationally representative cross-sectional survey. Hum. Vaccines Immunother. 2020, 2020, 1-10. [CrossRef]

23. Fisher, K.A.; Bloomstone, S.J.; Walder, J.; Crawford, S.; Fouayzi, H.; Mazor, K.M. Attitudes toward a potential SARS-CoV-2 vaccine: A survey of US adults. Ann. Intern. Med. 2020, 173, 964-973. [CrossRef] [PubMed]

24. Palamenghi, L.; Barello, S.; Boccia, S.; Graffigna, G. Mistrust in biomedical research and vaccine hesitancy: The forefront challenge in the battle against COVID-19 in Italy. Eur. J. Epidemiol. 2020, 35, 785-788. [CrossRef] [PubMed] 